\title{
Photo-identification of the vaquita (Phocoena sinus): THE WORLD'S MOST ENDANGERED CETACEAN ${ }^{1}$
}

\author{
Thomas A. Jefferson ${ }^{2, *}$, Paula A. Olson ${ }^{2}$, Thomas R. Kieckhefer ${ }^{3}$ and Lorenzo Rojas-Bracho ${ }^{4}$
}

The vaquita (Phocoena sinus) has been recognized as a rare and vulnerable species since its scientific discovery just over fifty years ago (Norris and McFarland, 1958). There are a number of potential threats facing the species, and its limited range in shallow waters of the upper portion of Mexico's Gulf of California is the smallest of any marine cetacean.

Without a doubt the primary threat is incidental kills of porpoises in various fisheries, mainly several gillnet fisheries (Rojas-Bracho and Taylor, 1999; Rojas-Bracho et al., 2006). The vaquita is listed as Critically Endangered on the IUCN Red List. With the recent discovery that the baiji (Lipotes vexillifer) is most likely extinct (Turvey et al., 2007), the vaquita is now recognized as the most endangered cetacean species in the world. There were estimated to be only about 150 vaquitas remaining in 2007 (Jaramillo-Legorreta et al., 2007).

In the autumn of 2008, a large-scale international effort to study the vaquita and develop methods to monitor its population status was conducted. As part of this effort, we investigated the feasibility of getting highquality photos of vaquitas and of using photoidentification methods. From 2-30 October 2008, we conducted small-vessel surveys for vaquitas from a shore-based station in San Felipe, Baja California Norte, Mexico. Each day, weather permitting, we traveled offshore to the region where past vaquita sightings had been concentrated (between San Felipe and Rocas Consag, a small island about $30 \mathrm{~km}$ offshore- JaramilloLegorreta et al., 2007).). We searched for vaquitas while the vessel was moving, but also periodically conducted 'stop and drift' searches, in which the vessel's engine and depth sounder were shut down, and 3-6 observers searched the area with naked eye and binoculars.

Two vessels were used: from 2-10 October, we used the Ema Luz, a 6.4-m outboard motor boat, which is similar to the vessels gillnet fishermen use in the area to tend their nets (locally called pangas). From 11-30 October, we used the Pancho Villa, a 17-m sportfishing vessel based in Puerto Peñasco. The Pancho Villa was much more stable and seaworthy, with a higher platform and much greater suitability for observations.

When vaquitas were observed, basic sighting data were collected (e.g., date, time, position, sighting conditions, group size, behavior), and we attempted to obtain photos. This could involve remaining with the boat engine turned off or in neutral (if the animals were within $150 \mathrm{~m}$ or so), or moving closer to the group at slow speed with the engine in gear. Photos were taken with Canon EOS 20D, 30D, and 40D digital cameras (8.2 or 10.1 megapixels) and a variety of L-series zoom and telephoto lenses, ranging up to $400 \mathrm{~mm}$ in focal length. A 1.4X or $2 X$ converter was used with some of the lenses. We conducted surveys on 20 days; poor weather (winds causing sea states of Beaufort 4 or above) prevented us from surveying on the remaining nine days. We searched $1,229 \mathrm{~km}$ while moving, and conducted 51 'stop and drift' searches making up a total of 50 hours. We sighted 13 groups of vaquitas (all between 18 and 30 October).

Vaquita sightings occurred both during 'stop and drift' searches $(n=7)$ and during searches while traveling $(n=6)$. Most sightings occurred in calm sea states of Beaufort 0 2 (winds $<12 \mathrm{~km} / \mathrm{h}$ ), with only one in a Beaufort 3 - the average sea state during vaquita sightings was $0.9 \pm$ s.d. $0.83(n=13)$. This emphasizes the importance of calm seas for sighting vaquitas. Group size ranged from 1-9 individuals, with a mean of $3.2 \pm$ s.d. 2.19. The largest groups generally appeared to be loose aggregations of several smaller subgroups of 1-4 individuals.

Calves were observed in at least four of the sightings, although these all appeared to be larger 'juveniles', rather than neonates. This is in agreement with the known spring calving season of the species (Hohn et al., 1996). Juveniles were slightly darker in color than the adults that accompanied them (as shown in Fig.1 of Brownell et al., 1987). Most of the groups observed appeared to be either milling/feeding or traveling. Responses to the vessel ranged from avoidance to no response, and in one case apparent attraction, as two individuals swam directly toward our idling vessel and passed almost directly beneath the bow.

Photos of vaquitas were taken during eight of the sightings; 1,653 frames were taken. On four different days vaquita images were obtained that were adequate for photoidentification. This is the first time that vaquitas have been photo-identified, although Silber et al. (1988, p. 64) did previously report a sighting of a female with 'two prominent nicks in the trailing edge' of the dorsal fin. We identified six individuals based on their natural markings (dorsal fin nicks, fin and body scars - Figure 1).

\footnotetext{
${ }^{1}$ Received on 5 March 2009. Accepted on 11 August 2009. Managed by Daniel Palacios.

${ }^{2}$ Southwest Fisheries Science Center, NOAA Fisheries. 3333 North Torrey Pines Court, La Jolla, CA 92037-1022 USA.

* Corresponding author, e-mail: sclymene@aol.com.

${ }^{3}$ Save the Whales. 1192 Waring Street, Seaside, CA 93955 USA.

${ }^{4}$ Programa de Investigación de Mamíferos Marinos, Instituto Nacional de Ecología (INE). C/o CICESE. Km 107, Carretera EnsenadaTijuana, Ensenada, BC 22860, Mexico.
} 

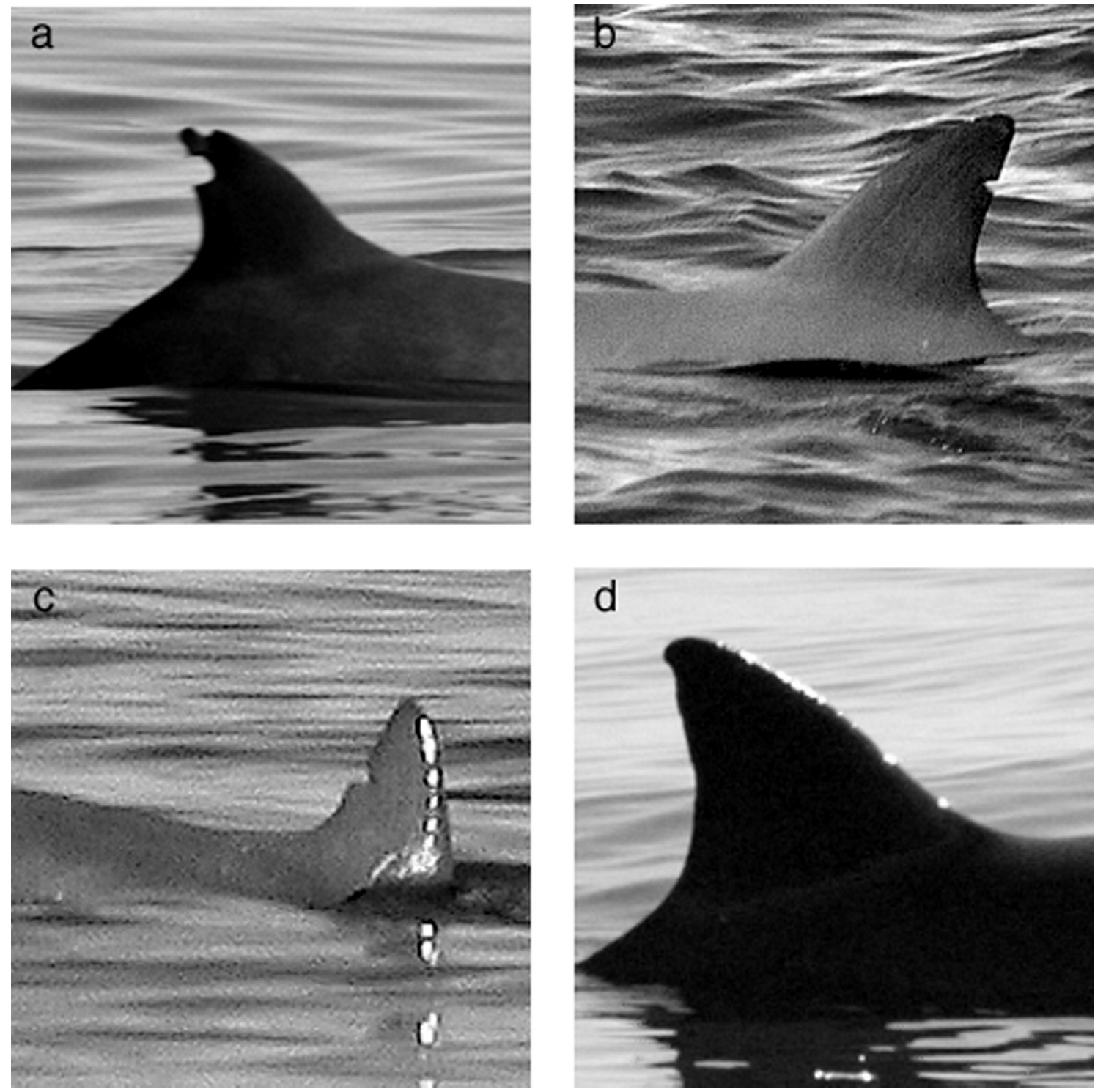

Figure 1. Four individual vaquitas that were photo-identified by dorsal fin shape and nicks: a. Nicola (a presumed female with two large notches), b. Topnick (an individual with a single triangular nick $2 / 3$ of the way up the dorsal fin), c. Midnick (an individual with a single triangular nick $1 / 2$ of the way up the dorsal fin), and d. Fingertip (a presumed female with an unusually-shaped dorsal fin).

However, two of these possessed only body scars that would likely not last long enough for multi-year identification (Figure 2). We also observed and photographed a number of scars on the heads of some individuals, although these were deemed inadequate for photo-ID, based on how infrequently vaquitas show their heads. All photographed individuals appeared healthy, with no evidence of malnutrition or dermal disease.

Many porpoises did not appear to possess usable distinctive features on their backs or dorsal fins, even in high-quality, sharp images. We obtained goodquality photos of two juvenile individuals, but neither of these was individually identifiable. Of the 13-17 different adults that we estimate we photographed well over the study, six individuals could be identified reliably, at least within one field season. If this small sample is representative of the population, it suggests that between $35 \%$ and $46 \%$ of adults possess markings that would allow them to be identified within a season.

Based on this sample, and considering only those with long-term markings, an estimated $24-31 \%$ of adults would be suitable for long-term photo-identification. This is higher than the $17-21 \%$ estimated for Dall's porpoise (Phocoenoides dalli - Miller, 1990), and might be related to the relatively larger dorsal fins of vaquitas and the more shallow nature of their habitat (i.e., contact with the sea floor would presumably increase scarring opportunities). Although attempts have been made to identify individual harbor (Phocoena phocoena - Watson, 1976; 

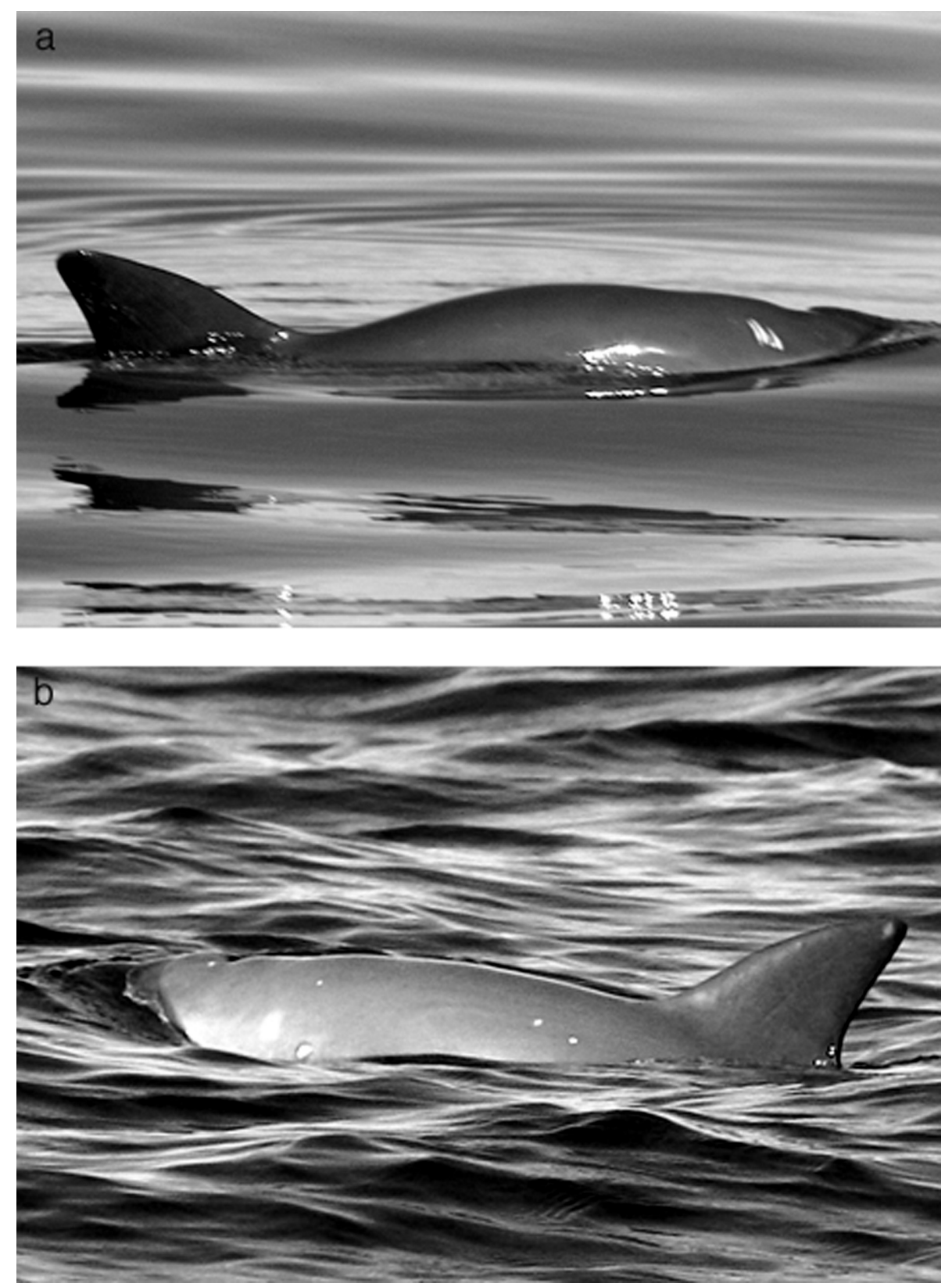

Figure 2. Two vaquita individuals that were identified by body scarring. Neither of these animals is considered to be identifiable in the long term.

Watson and Gaskin, 1983) and finless (Neophocaena phocaenoides - Jefferson, unpubl. data) porpoises by natural markings, photo-identification techniques have never been successfully applied to other species of the genus Phocoena. This study has demonstrated that, despite their rarity and cryptic nature, vaquitas can be photo-identified. We are optimistic that future efforts can obtain even better photos, and that individual vaquitas can be tracked over time. Even limited success at photoidentification of this critically-endangered species may provide valuable information. In fact, with any kind of tagging work being infeasible for such a rare species, photo-identification may be the only way to get at many critical pieces of information. Any future photo-identification work will be facilitated by new technological advances (such as digital SLR cameras with high-resolution video), and should attempt to use a relatively large $(>15 \mathrm{~m})$, stable vessel that allows for eye heights of at least several meters above the surface; pangas are not good vessels for this kind of work. In order to learn more about the vaquita, we plan to pursue further photo-identification studies. 


\section{Acknowledgements}

Many people and organizations were involved in the successful completion of this project. It would not have been possible without the collaboration of our colleagues from NOAA, especially B. Taylor, L. Ballance, R. Pitman, S. Mesnick, A. Henry, S. Rankin, N. Kellar, and G. SerraValente. C. Johnson was great field partner and we thoroughly enjoyed our times together at sea and on land. A. Jaramillo was also helpful, and we were fortunate to have the assistance of G. Silber on one day. We would like to thank our expert boat drivers and crew: A. Herrera, R. Ramirez, A. Vasquez, Ricardo and Pablo. H. Chan and L. Jefferson assisted us in the field. This project was funded by the Whale and Dolphin Conservation Society (UK), World Wildlife Fund (US), Natural Resources Defense Council (US), and a US foundation that prefers to remain anonymous. Cetos Research Organization provided financial support, and we particularly thank A. Zoidis. The photos were taken under permit (Oficio No. DR/488/08 from the Comisión Nacional de Áreas Naturales Protegidas (CONANP/Secretaría del Medio Ambiente y Recursos Naturales (SEMARNAT), within a natural protected area subject to special management and decreed as such by the Mexican Government. J. Campoy was instrumental in helping to obtain our permit. Comments from B. Taylor, J. Urbán, W. Perrin, and S. Mesnick improved the manuscript.

\section{References}

Brownell, R.L., Findley, L.T., Vidal, O., Robles, A. and Manzanilla, N.S. (1987) External morphology and pigmentation of the vaquita, Phocoena sinus (Cetacea: Mammalia). Marine Mammal Science 3: 22-30.

Hohn, A.A., Read, A.J., Fernandez, S., Vidal, O. and Findley, L.T.
(1996) Life history of the vaquita, Phocoena sinus (Phocoenidae, Cetacea). Journal of Zoology, London 239: 235-251.

Jaramillo-Legoretta, A.M., Rojas-Bracho, L. and Gerrodette, T. (1999) A new abundance estimate for vaquitas: first step for recovery. Marine Mammal Science 15: 957-973.

Jaramillo-Legoretta, A., Rojas-Bracho, L., Brownell JR., R.L., Read, A.J., Reeves, R.R., Ralls, K. and Taylor, B.L. (2007) Saving the vaquita: Immediate action, not more data. Conservation Biology 21: 1653-1655.

MilLeR, E.J. (1990) Photo-identification techniques applied to Dall's porpoise (Phocoenoides dalli) in Puget Sound, Washington. Reports of the International Whaling Commission Special Issue 12: 429-437.

NorRIS, K.S. AND McFarLAND, W.N. (1958) A new harbor porpoise of the genus Phocoena from the Gulf of California. Journal of Mammalogy 39: 22-39.

Rojas-BRACHO, L. AND TAYLOR, B.L. (1999) Risk factors affecting the vaquita (Phocoena sinus). Marine Mammal Science 15: 974-989.

Rojas-Bracho, L., Reeves, R.R. and Jaramillo-Legoretta, A. (2006) Conservation of the vaquita Phocoena sinus. Mammal Review 36: $179-216$.

Silber, G.K., NeWcomer, M.W. And Barros, G.J. (1988) Observations on the behavior and ventilation cycles of the vaquita, Phocoena sinus. Marine Mammal Science 4: 62-67.

Turvey, S.T., Pitman, R.L., Taylor, B.L., Barlow, J., Akamatsu, T., Barrett, L.A., Zhao, X., Reeves, R.R., Stewart, B.S., Wang, K., Wei, Z., Zhang, Z., Pusser, L.T., Richlen, M., Brandon, J.R. AND Wang, D. (2007) First human-caused extinction of a cetacean species. Biology Letters 3: 537-540.

WATSON, A.P. (1976) The diurnal behaviour of the harbor porpoise (Phocoena phocoena L.) in the coastal waters of the western Bay of Fundy. M.Sc. thesis, University of Guelph, Ontario, Canada, 93 pp.

Watson, A.P. AND Gaskin, D.E. (1983) Observations on the ventilation cycle of the harbour porpoises Phocoena phocoena (L.) in coastal waters of the Bay of Fundy. Canadian Journal of Zoology 61: 126-132. 